\title{
Statistical Study of foF2 Diurnal Variation at Dakar Station from 1971 to 1996: Effect of Geomagnetic Classes of Activity on Seasonal Variation at Solar Minimum and Maximum
}

\author{
Ali Mahamat Nour ${ }^{1}$, Ouattara Frédéric ${ }^{1,2}$, Zerbo Jean Louis ${ }^{2,3}$, \\ Gyébré Aristide Marie Frédéric ${ }^{1,2}$, Nanéma Emmanuel1,2,4, Zougmoré François ${ }^{1}$ \\ ${ }^{1}$ Laboratoire de Matériaux et Environnement (LAME), UFR SEA Université de Ouagadougou, Ouagadougou, \\ Burkina Faso \\ ${ }^{2}$ Laboratoire de Recherche en Energétique et Météorologie de l'Espace (LAREME), Université de Koudougou, \\ Koudougou, Burkina Faso \\ ${ }^{3}$ Institut des Sciences Exactes et Appliquées (ISEA), Université Polytechnique de Bobo Dioulasso, Bobo \\ Dioulasso, Burkina Faso \\ ${ }^{4}$ Centre National de Recherches Scientifiques et Techniques (CNRST), Institut de Recherches Scientifiques \\ Appliquées et Technologies (IRSAT), Ouagadougou, Burkina Faso \\ Email: fojals@yahoo.fr, ouattarafred@yahoo.fr
}

Received 7 February 2015; accepted 6 March 2015; published 11 March 2015

Copyright (C) 2015 by authors and Scientific Research Publishing Inc.

This work is licensed under the Creative Commons Attribution International License (CC BY).

http://creativecommons.org/licenses/by/4.0/

(c) (i) Open Access

\section{Abstract}

The statistical study of F2 layer critical frequency at Dakar station from 1971 to 1996 is carried out. This paper shows foF 2 statistical diurnal for all geomagnetic activities and all seasons and that during solar maximum and minimum phases. It emerges that foF2 diurnal variation graphs at Dakar station exhibits the different types of foF2 profiles in African EIA regions. The type of profile depends on solar activity, season and solar phase. During solar minimum and under quiet time condition, data show the signature of a strength electrojet that is coupled with intense counter electrojet in the afternoon. Under disturbed conditions, mean intense electrojet is observed in winter during fluctuating and recurrent activities. Intense counter electrojet is seen under fluctuating and shock activities in all seasons coupled with strength electrojet in autumn. In summer and spring under all geomagnetic activity condition, there is intense counter electrojet. During solar maximum, in summer and spring there is no electrojet under geomagnetic activity conditions. Winter shows a mean intense electrojet. Winter and autumn are marked by the signature of the reversal electric field.

How to cite this paper: Nour, A.M., Frédéric, O., Louis, Z.J., Frédéric, G.A.M., Emmanuel, N. and François, Z. (2015) Statistical Study of foF2 Diurnal Variation at Dakar Station from 1971 to 1996: Effect of Geomagnetic Classes of Activity on Seasonal Variation at Solar Minimum and Maximum. International Journal of Geosciences, 6, 201-208. 


\section{Keywords}

\section{foF2 Diurnal Variation, Solar Cycle Phases, Geomagnetic Activity Classes, Seasonal Effects, E Region Electric Currents}

\section{Introduction}

Geomagnetic activity, defined as the disturbance of the geomagnetic field due to external source [1], has been divided into four classes of activity [2]-[5] These classes are: quiet activity due to slow solar wind, shock activity due to CMEs (Coronal Mass Ejections), recurrent activity provoked by high speed solar wind coming from coronal hole and fluctuating activity constituted by the other activities which are not clear [4]. The impact of each class of activity in the critical frequency of F2 layer (foF2) has been study through Ouagadougou station (Lat: $12.4^{\circ} \mathrm{N}$; Long: $358.5^{\circ} \mathrm{E}$; dip: $1.43^{\circ}$ ) foF2 variability [6]-[9] and Dakar (Lat: $14.8^{\circ} \mathrm{N}$; Long: $342.6^{\circ} \mathrm{E}$, dip: $8.44^{\circ}$ ) station foF2 variability [10]. The first foF2 statistical variation for an African Equatorial Ionization Anomaly (EIA) station has been performed by Ouattara and Amory Mazaudier [9] at Ouagadougou station located at the trough of ionization. This paper, the second one that focuses on foF2 statistical variation concerns Dakar station situates between the crest and the trough of the EIA region of African sector from 1971 to 1996 . Our objective in statistical works is, on the one hand, to investigate existing models predictions by comparing the statistical experimental results coming from long series data base with models' results. On the second hand, to contribute to space weather study by determining ionosphere variability under different types of solar activity and that for different seasons and solar cycle phases. The present study goal is to contribute to space weather study. Dakar station is used because foF2 variation comparative study through its long term trend variation and diurnal variation shows the particularity of Dakar station (see [11]-[13]). For this paper, our attention is only focused on foF2 statistical diurnal variation during solar minimum and maximum phases.

\section{Materials and Methods}

The data used in this study concern Dakar station (Lat: $14.8^{\circ} \mathrm{N}$; Long: $342.6^{\circ} \mathrm{E}$, dip: $8.44^{\circ}$ ) in Sénégal provided by Télécom Bretagne. We analyze foF2 statistical diurnal variation from 1971 to 1996 . That period involved three solar minimum and two solar maximum. In this paper, we neglect the impact of long term trend in data because Gnabahou et al. [12] at Dakar station showed that on the one hand there is no difference between disturbed and quiet time periods for foF2 yearly variation and on the other hand the long term trend slop at Dakar station is weak.

For the determination of solar cycle phases, we use sunspot number $\mathrm{R}_{\mathrm{Z}}$ and follow Ouattara et al. [8] method. According to their method solar minimum year is given by $\mathrm{R}_{\mathrm{Z}}<20$ and solar maximum year is obtained by taking $\mathrm{R}_{\mathrm{Z}}>100$. It is important to note that for small solar cycles (solar cycles with sunspot number maximum (Rz max) less than 100) the maximum phase is obtained by considering $R_{z}>0.8 \times R_{Z}$ max. Solar increasing phase years is given by $20 \leq R_{Z} \leq 100$ and $R_{z}$ greater than the previous year's value. Solar decreasing phase is obtained by $100 \geq R_{Z} \geq 20$ and $R_{Z}$ less than the previous year's value. Keep in mind that we will only consider solar minimum and maximum in this work.

For the determination of geomagnetic conditions, we use pixel diagrams (Figure 1 example of pixel diagram; see Ouattara and Amory Mazaudier [14] for more details) built by using 1) Mayaud [15] [16] geomagnetic index aa by considering its daily mean value Aa, 2) the date of Sudden Storm Commencement (SSC) and 3) color code that allow us to identify the four classes of geomagnetic activity. In pixel diagram, quiet time condition is highlighted by white and blue colors and given by Aa $\leq 20 \mathrm{nT}$. The other conditions namely disturbed conditions that take together the three other conditions are given by $\mathrm{Aa}>20 \mathrm{nT}$ and highlighted by the other colors (green, yellow, orange, red and olive red).

For seasonal study, the following seasons are considered: winter (December, January and February), spring (March, April, May), summer (June, July, August) and autumn (September, October and November).

To perform the statistical hourly foF2 values we follow Ouattara and Amory Mazaudier [9] method. Therefore, the following equations are used: 


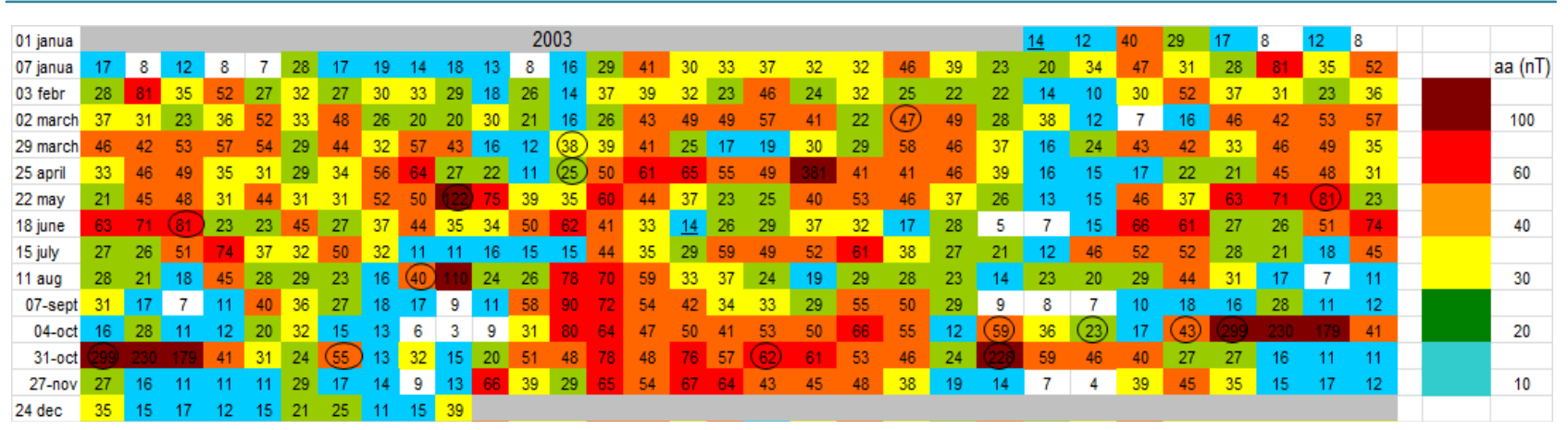

Figure 1. An example of pixel diagram (2003 year pixel diagram). Circle indicates the date of SSC.

\subsection{Geomagnetic Activity Impact Evaluation}

The hourly foF2 values for geomagnetic quiet conditions from 1971-1996 ( foF2 $_{\text {Geomag }}^{\text {Hourly }}$ ) are determined by using Equation (1):

$$
\mathrm{foF}^{\text {Georly }}=\frac{\sum_{\text {Geo }}^{\mathrm{Nc}} \mathrm{foF} 2_{\text {Cycle }}^{\text {Hourly }}}{\mathrm{Nc}}
$$

In this equation, foF $2_{\text {Cycle }}^{\text {Houly }}$ is the hourly mean foF2 value for the considered solar cycle phase and Nc the number of solar cycle phase involved in the period 1971-1996.

From Table 1, it can be seen for our period involved, three solar minimum phases, two solar maximum phases, three solar decreasing phases and two solar increasing phases. Only solar maximum and minimum phases will be considered as previously noted. By using Equation (1), we determine the 24 hours mean values of foF2 for each type of geomagnetic class of activity by considering the whole 9496 days of the 26 years involved (20 years with 365 days and 6 years with 366 days). Daily geomagnetic activity is evaluated by using pixel diagrams (see [2] [3] [14]).

\subsection{Solar Cycle Phase Impact Evaluation}

The mean hourly foF2 value of a solar cycle phase ( $f \circ F 2_{\text {Cycle }}^{\text {Houly }}$ ) is carried out through Equation (2):

$$
\mathrm{foF}_{\text {Cycle }}^{\text {Hourly }}=\frac{\sum_{j=1}^{\mathrm{Ny}} \mathrm{foF} 2_{\text {Year }}^{\text {Hourly }}}{\mathrm{Ny}}
$$

In this equation, foF2 $2_{\text {Year }}^{\text {Hourly }}$ corresponds to the mean hourly foF2 value of the considered year and Ny the number of year involved in the considered solar cycle phase. The number of year per solar cycle phase can be obtained by counting the number of year of each solar cycle phase shown in Table 1.

foF 2 Yourly is given by Equation (3):

$$
\mathrm{foF} 2_{\text {Yoar }}^{\text {Hourly }}=\frac{\sum_{k=1}^{\mathrm{Nm}} \mathrm{foF} 2_{\text {Month }}^{\text {Hourly }}}{\mathrm{Nm}}
$$

In Equation (3), foF2 $2_{\text {Montl }}^{\text {Honth }}$ corresponds to the monthly hourly mean value of foF2 and Nm the number of available month involved in the considered year.

\subsection{Seasonal Study Impact Evaluation}

For seasonal study, foF2 ${ }_{\text {Month }}^{\text {Hour }}$ is obtained by utilizing Equation (4):

$$
\mathrm{foF}_{\text {Month }}^{\text {Hourly }}=\frac{\sum_{l=1}^{\mathrm{Nd}} \mathrm{foF}_{\text {Day }}^{\text {Hourly }}}{\mathrm{Nd}}
$$


Table 1. Solar cycle phases in the period 1971-1996.

\begin{tabular}{|c|c|c|c|c|}
\hline Number of solar cycle & Minimum $\mathrm{R}_{\mathrm{z}}<20$ & Increasing $20 \leq \mathrm{R}_{\mathrm{Z}} \leq 100$ & Maximum $\mathrm{R}_{\mathrm{z}}>100$ & Decreasing $100 \geq R_{Z} \geq 20$ \\
\hline 20 & & & & 1971-1975 \\
\hline 21 & 1976 & $1977-1978$ & 1979-1982 & 1983-1985 \\
\hline 22 & 1986 & $1987-1988$ & 1989-1991 & 1992-1995 \\
\hline 23 & 1996 & & & \\
\hline
\end{tabular}

In the previous equation, $\mathrm{foF}_{\text {Day }}^{\text {Hourly }}$ is an hourly foF2 value for a geomagnetic class day and $\mathrm{Nd}$ the number of geomagnetic class day involved in the month considered.

\section{Results}

In the present paper, we present foF2 diurnal variation during solar minimum and maximum phases under the four geomagnetic conditions and for different seasons.

Figure 2 and Figure 3 show seasonal variability of diurnal variation of foF2 during all geomagnetic activities for solar cycle minimum phase and solar maximum phase, respectively. In these figures, blue graph corresponds to winter, red curve to spring; black graph is devoted to autumn and green curve to summer.

Figure 2(a) shows the first peak at $1000 \mathrm{LT}$ and the second at $1800 \mathrm{LT}$. The highest morning peak and afternoon peak is seen in autumn graph with $9.29 \mathrm{MHz}$ and $10.64 \mathrm{MHz}$ as foF2 value respectively. Winter foF2 values are superior to summer foF2 values; this shows winter anomaly. There is equinoctial asymmetry during daytime. There is no night time peak during this period.

In Figure 2(b), one can observed the same foF2 diurnal variation as for quiet time (panel a). The highest morning peak value is $9.27 \mathrm{MHz}$ for winter curve; that of afternoon peak is $11.14 \mathrm{MHz}$ for autumn graph. Night time peak is observed in autumn graph at $2100 \mathrm{LT}$ with 7.29 MHz. The principal difference between quiet time curves (panel a) and fluctuating time curves (panel b) is the presence of night time peak. One can see the presence of equinoctial asymmetry (autumn foF2 values are superior to those of spring) i.e. September/October peak superior to March/April.

Figure 2(c) highlights the absence of shock activity during summer. A fairly double peak is observed in autumn curves at $1000 \mathrm{LT}$ and $1700 \mathrm{LT}$ with $10.25 \mathrm{MHz}$ and $11.8 \mathrm{MHz}$, respectively. It can be seen that at daytime spring values are superior to those of autumn. This observation points out the presence of equinoctial asymmetry. Night peak is exhibited by all recorded season.

Figure 2(d) shows at daytime equinoctial anomaly with autumn peak superior to that of spring. Morning peak is shown at (1) $1000 \mathrm{LT}$ with $9.89 \mathrm{MHz}$ during winter and at (2) $1200 \mathrm{LT}$ with $10.1 \mathrm{MHz}$ during autumn. Autumn graph highlights night peak at $2100 \mathrm{LT}$ with $8.43 \mathrm{MHz}$ while winter curve shows this peak at $2000 \mathrm{LT}$ with $8.25 \mathrm{MHz}$.

For summarizing, during solar minimum only under autumn, foF2 diurnal variation graph show noon bite out profile with predominance afternoon peak. During all time geomagnetic conditions, summer and spring graph exhibit afternoon profile. Winter curve shows morning peak (panels a, b and d) except shock activity where one observe a plateau profile at $06 \mathrm{~h} 00$ - $14 \mathrm{~h} 00$ (panel c).

F2 layer density is the highest under recurrent condition and the lowest during quiet condition. It can be retained that quiet foF2 density < fluctuating foF2 density < shock foF2 density < recurrent foF2 density.

Except the profile type, seasonal effect is non-perceptible under shock condition because graphs are merged.

The night peak is seen in autumn graph under disturbed periods (panels b, c and d). Shock activity exhibits this peak at all seasons.

Figure 3(a) shows equinoctial asymmetry as autumn foF2 values are superior to those of spring. As winter foF2 values are superior to those of summer data highlight winter anomaly. Autumn curve present noon bite out profile with morning peak at $1000 \mathrm{LT}$ with $13.99 \mathrm{MHz}$ and Afternoon peak is situated at $1700 \mathrm{LT}$ with foF2 values $13.66 \mathrm{MHz}$. Winter curve show a morning peak profile with $14.29 \mathrm{MHz}$ as foF2 values. Spring graph shows plateau profile with $13.05 \mathrm{MHz}$ as foF2 value and the curve of summer exhibits dome profile with 12.16 $\mathrm{MHz}$ at $1700 \mathrm{LT}$.

Figure 3(b) exhibits equinoctial asymmetry with autumn foF2 values superior to those of spring. Winter 

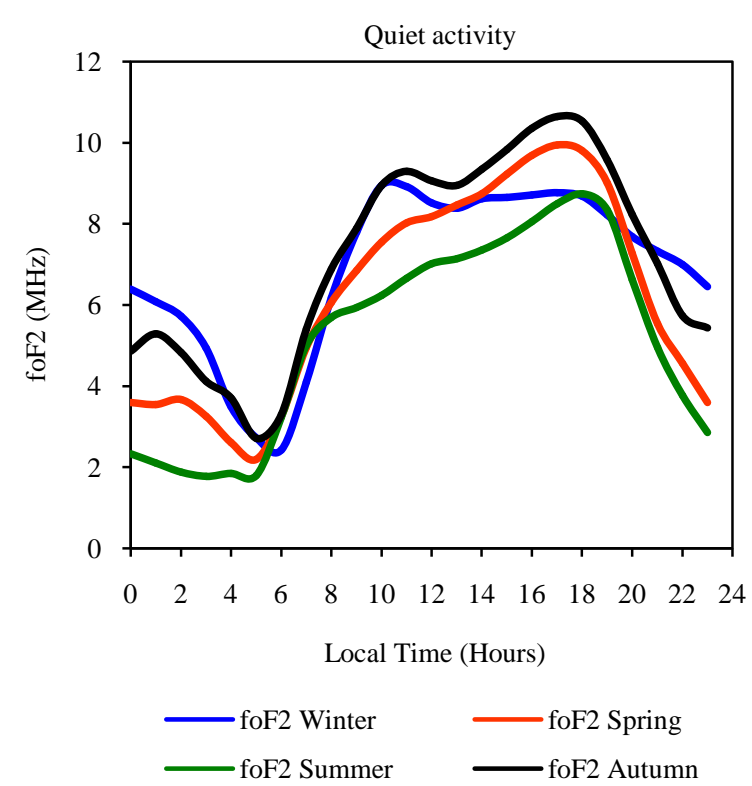

(a)
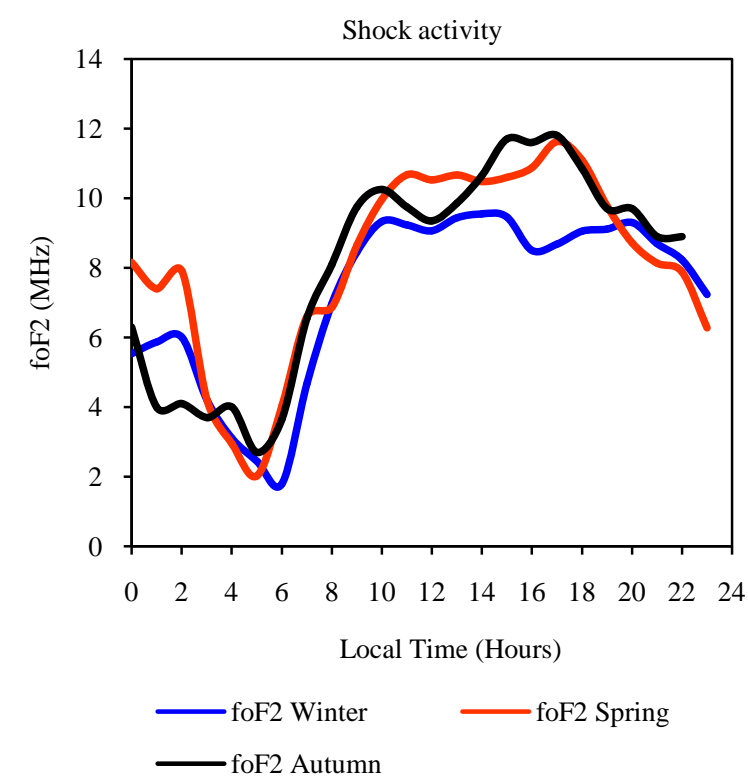

(c)

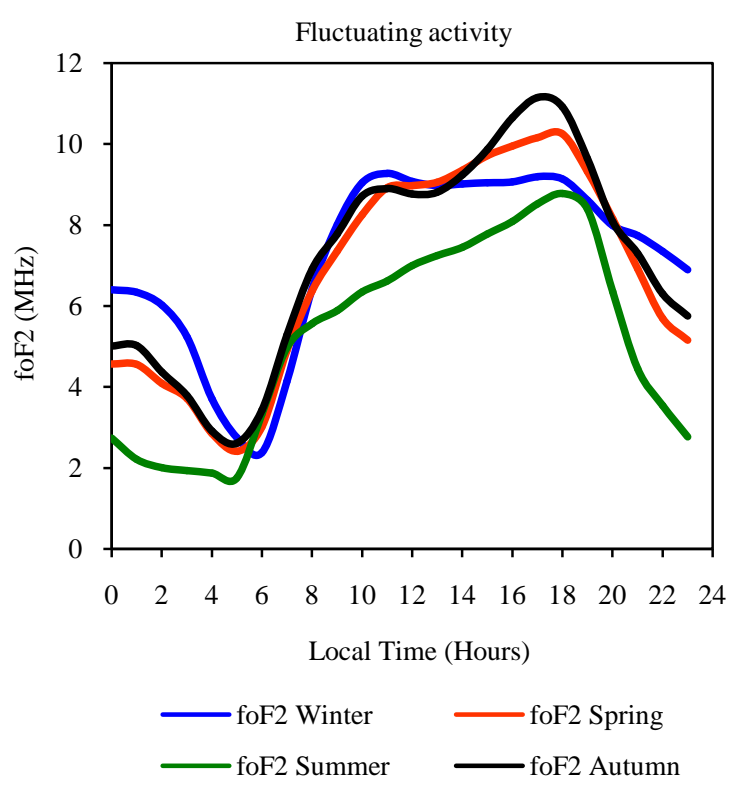

(b)

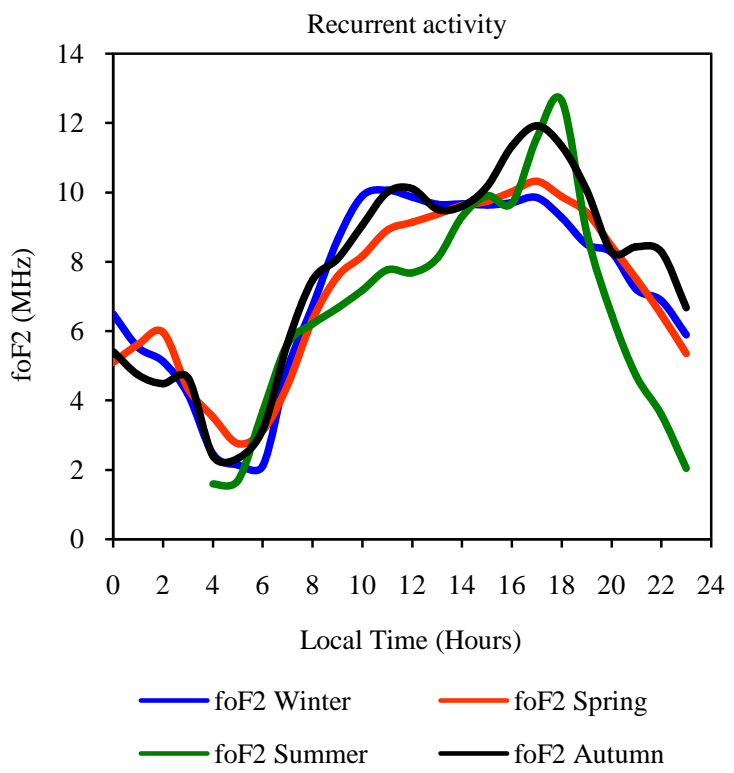

(d)

Figure 2. Seasonal and diurnal foF2 variation under quiet time (panel a), Fluctuating activity (panel b) shock activity (panel c) and recurrent activity (panel d) conditions for solar minimum.

anomaly is shown by the values of winter foF2 superior to those of summer. Double peak is seen in autumn curve with $14 \mathrm{MHz}$ as peak values and located at $1000 \mathrm{LT}$ and $1700 \mathrm{LT}$ for morning peak and afternoon peak, respectively. Winter curve presents morning peak profile where the peak is situated at $1000 \mathrm{LT}$ with $14.16 \mathrm{MHz}$. Spring profile is that plateau with $13.44 \mathrm{MHz}$ as foF2 maximum value. Summer curve highlights dome profile with the maximum located at $1700 \mathrm{LT}$ with $12.69 \mathrm{MHz}$.

Figure 3(c) concerns shock activity graphs. Winter anomaly is shown by data profiles. Equinoctial anomaly shown here is characterized by autumn data values superior to those of spring. Winter graph shows morning peak located at $1000 \mathrm{LT}$ with 14.36 MHz. Spring and autumn curves show fairly plateau profile with $13.40 \mathrm{MHz}$ as foF2 value. Dome profile is presented by summer graph with the maximum located at 1600 LT with 12.88 $\mathrm{MHz}$ as foF2 value. 

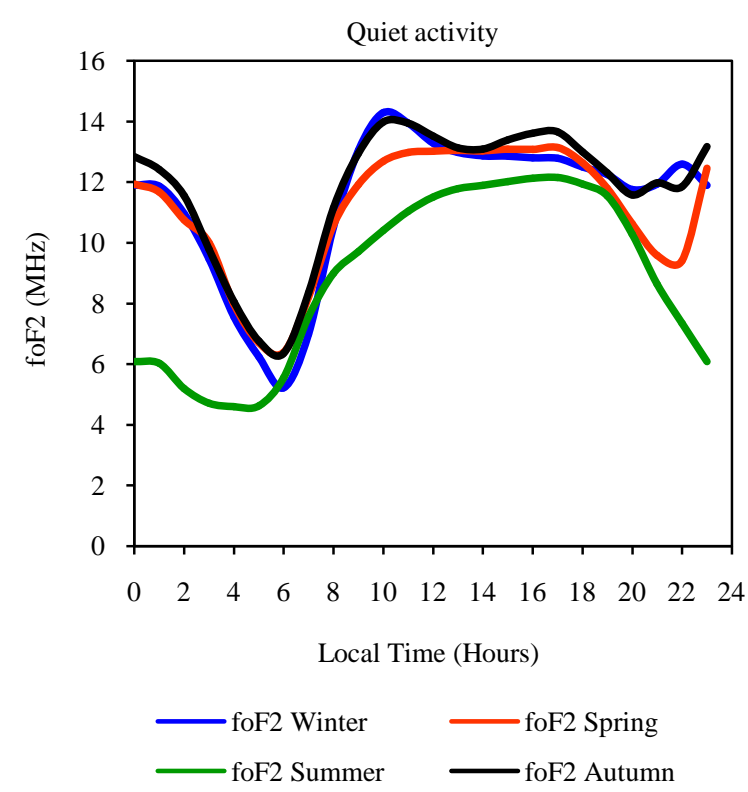

(a)
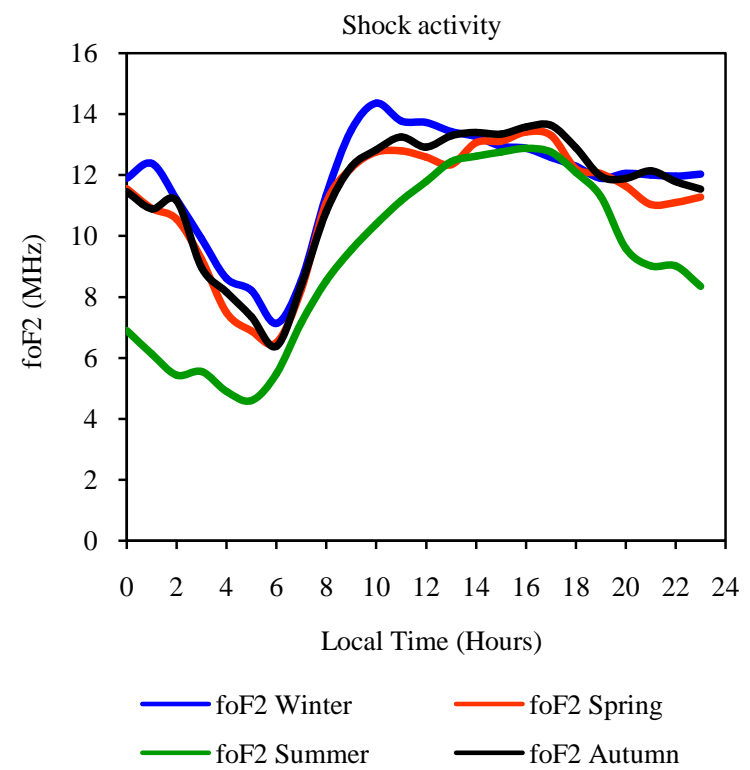

(c)
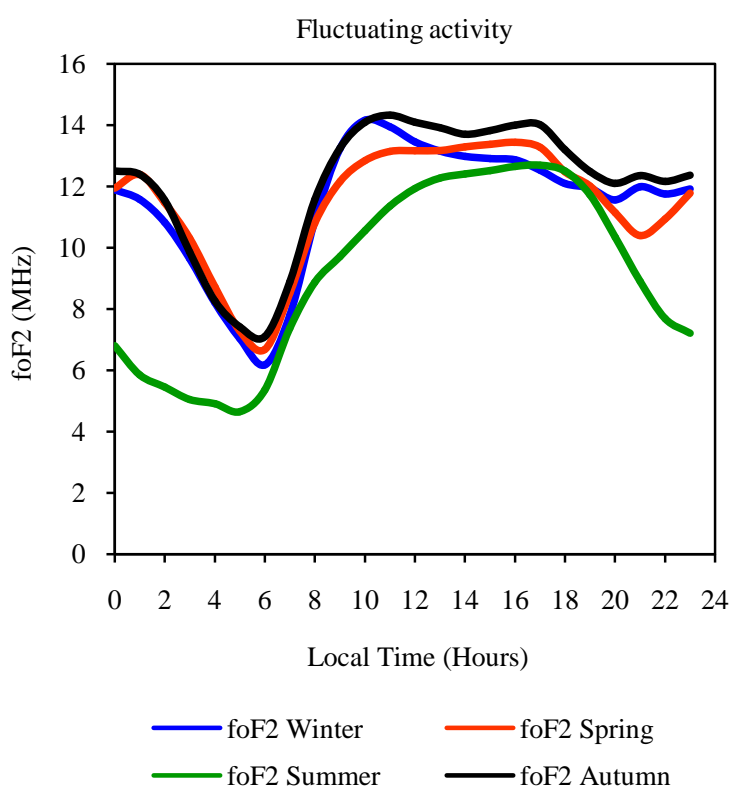

(b)

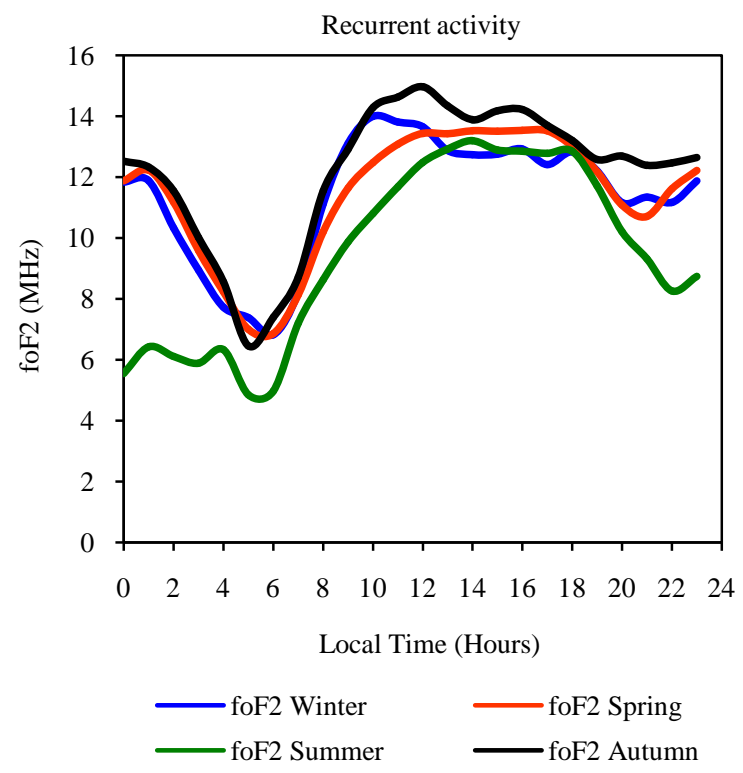

(d)

Figure 3. The same as Figure 2 but for solar maximum.

Figure 3(d) is devoted to recurrent activity. It can be seen that winter values are superior to those of summer. This observation shows winter anomaly.

Autumn values are superior to those of the other seasons. Except autumn graph the others are merged and have the same behavior. There is equinoctial asymmetry during this activity. Winter graph shows morning peak profile where the peak is situated at $1000 \mathrm{LT}$ with $14 \mathrm{MHz}$; autumn exhibits the noon bite out while spring curve is plateau profile and dome profile is seen at summer.

Night time peak is seen at $2000 \mathrm{LT}$ for autumn curve with $12.69 \mathrm{MHz}$ and winter graphs at 2100 with 11.34 $\mathrm{MHz}$ as foF2 values.

For summarizing at solar maximum, under all geomagnetic activities conditions, dome profile is shown in summer, plateau profile is observed in spring graph and morning peak profile is seen in winter. Except shock activity, autumn presents a noon bit out profile. 
Winter and autumn curves present night time peak at all geomagnetic activities. All graphs, under shock activity show night time peak. Except in summer, all graphs are merged under shock and recurrent activities.

\section{Discussion and Conclusions}

The five types of foF2 profile observed at Ouagadougou station (Long: $358.5^{\circ} \mathrm{E}$; Lat: $12.4^{\circ} \mathrm{N}$; dip: $+1.45^{\circ}$ ) by Fayot and Vila [17] are also seen here at Dakar station (Long: $342.6^{\circ} \mathrm{E}$; Lat: $14.8^{\circ} \mathrm{N}$; dip: $+5.53^{\circ}$ ): dome or D profile, noon bite out or B profile, morning peak or M profile, afternoon peak or reversed or R profile and plateau or P profile. Based on the fact that foF2 is able to describe the distribution of $\mathrm{E}$ layer electric current through the study of ground recorded magnetic field variations, Dunford [18], Vassal [19], Vassal [20], Acharya [21] and Acharya [22] show that it is possible to link ionosphere variability to the nature, the force or the absence of E region electric currents. Therefore, Vassal [20] relied the above different types of foF2 profiles of West Africa equatorial region on different types of E layer electric current (electrojet and counter electrojet). He attributed to $\mathrm{D}$ and $\mathrm{P}$ profiles the absence of electrojet, to $\mathrm{R}$ profile the presence of intense counter electrojet, to $M$ profile the presence mean intensity electrojet and to B profile the presence of strength electrojet.

By taking into account the above relationship between E region electric current and foF2 diurnal variation, one can assert that:

During solar minimum and: 1) under quiet time condition there is a strength electrojet at daytime coupled with intense counter electrojet at the afternoon; 2) under fluctuating condition we observe the presence of mean intense electrojet in winter, intense counter electrojet for the other seasons coupled with strength electrojet in autumn; 3) under shock activity, we note the presence of an intense counter electrojet for the seasons involved coupled with a strength electrojet in autumn; 4) under recurrent condition, mean intense electrojet is observed in winter, strength electrojet in autumn and intense counter electrojet in the others seasons. As in foF2 diurnal profile the presence of trough around midday observed in noon bite out profile expresses the signature of the vertical drift ExB (see [23]-[26]), it can be retained that only during quiet time condition and in autumn foF2 profiles express the signature of the vertical drift ExB. Fairly under all geomagnetic activities and in autumn this signature is observed. Moreover, it is well-known that a night time peak in foF2 diurnal variation graph is the signature of the reversal electric field in equatorial region (see [23]-[26]). Therefore, this signature is observed during the disturbed condition in autumn graph under all geomagnetic conditions and also in winter except under fluctuating activity.

During solar maximum and in: 1) summer and spring, the absence of an electrojet is seen under the all geomagnetic activities; 2) winter, we observe presence of mean intense electrojet; and autumn we note presence strength electrojet except during the shock activity; 3) winter and autumn under all geomagnetic conditions, we observe the signature of the reversal electric field; this signature is also observed for all seasons under shock activity; 4) all seasons, there is no seasonal effect under shock activity except in summer.

\section{References}

[1] Legrand, J.P. (1984) Elementary Introduction of Cosmic Physics and Solar Terrestrial Physics, Area of Southern and Antarctic French Land, 306.

[2] Legrand, J.P. and Simon, P.A. (1989) Solar Cycle and Geomagnetic Activity: A Review for Geophysicists. Part I. The Contributions to Geomagnetic Activity of Shock Waves and of the Solar Wind. Annals of Geophysics, 7, 565-578.

[3] Simon, P.A., and Legrand, J.P. (1989) Solar Cycle and Geomagnetic Activity: A Review for Geophysicists. Part II. The Solar Sources of Geomagnetic Activity and Their Links with Sunspot Cycle Activity. Annals of Geophysics, 7, 579-594.

[4] Richardson, I.G., Cliver, E.W. and Cane, H.V. (2000) Sources of Geomagnetic Activity over the Solar Cycle: Relative Importance of Coronal Mass Ejections, High-Speed Streams, and Slow Solar Wind. Journal of Geophysical Research, 105, 18200-18213. http://dx.doi.org/10.1029/1999JA000400

[5] Richardson, I.G. and Cane, H.V. (2002) Sources of Geomagnetic Activity during Nearly Three Solar Cycles (19722000). Journal of Geophysical Research, 107, 1187.

Ouattara, F. (2013) IRI-2007 foF2 Predictions at Ouagadougou Station during Quiet Time Periods from 1985 to 1995. Archives of Physics Research, 4, 12-18.

[6] Ouattara, F. (2009) Contribution à l'étude des relations entre les deux composantes du champ magnétique solaire et l'ionosphère équatoriale. Thèse de Doctorat d'Etat, Université Cheikh Anta Diop, Dakar. 
[7] Ouattara, F. and Zerbo, J.L. (2011) Ouagadougou Station F2 layer Parameters Yearly and Seasonal Variations during Severe Geomagnetic Storms Generated by CMEs and Fluctuating wind Streams. International Journal of Physical Sciences, 6, 4854-4860.

[8] Ouattara, F., Gnabahou, D.A. and Mazaudier, C.A. (2012) Seasonal, Diurnal and Solar-Cycle Variations of Electron Density at Two West Africa Equatorial Ionization Anomaly Stations. International Journal of Geophysics, 2012, Article ID: 640463. http://dx.doi.org/10.1155/2012/640463

[9] Ouattara, F. and Mazaudier, C.A. (2012) Statistical Study of the Diurnal Variation of the Equatorial $F_{2}$ Layer at Ouagadougou from 1966 to 1998. Journal of Space Weather Space Climate, 2, 1-10. http://dx.doi.org/10.1051/swsc/2012019

[10] Gnabahou, A. and Ouattara, F. (2012) Ionosphere Variability from 1957 to 1981 at Djibouti Station. European Journal of Scientific Research, 73, 382-390.

[11] Gnabahou, D.A., Elias, A.G. and Ouattara, F. (2013) Long-Term Trend of foF $_{2}$ at a West-African Equatorial Station Linked to Greenhouse Gases Increase and Dip Equator Secular Displacement. Journal of Geophysical Research, 118, 3909-3913. http://dx.doi.org/10.1002/jgra.50381

[12] Gnabahou, D.A., Ouattara, F., Nanéma, E. and Zougmoré, F. (2013) foF2 Diurnal Variability at African Equatorial Stations: Dip Equator Secular Displacement Effect. International Journal of Geosciences, 4, 1145-1150. http://dx.doi.org/10.4236/ijg.2013.48108

[13] Ouattara, F., Gnabahou, A. and Mazaudier, C.A. (2012) Seasonal, Diurnal and Solar-Cycle Variations of Electron Density at Two West Africa Equatorial Ionization Anomaly Stations. International Journal of Geophysics, 2012, Article ID: 640463, 9 p.

[14] Ouattara, F., Amory-Mazaudier, C., Fleury, R., Lassudrie-Duchesne, P., Vila, P. and Petitdidier, M. (2009) West African Equatorial Ionospheric Parameters Climatology Based on Ouagadougou Ionosonde Station Data from June 1966 to February 1998. Annales Geophysicae, 27, 2503-2514. http://dx.doi.org/10.5194/angeo-27-2503-2009

[15] Mayaud, P.N. (1971) A Measurement of Planetary Magnetic Activity Based on Two Antipodal Observatories. Annales Geophysicae, 27, 67-71.

[16] Mayaud, P.N. (1972) The aa Indices: A 100-Year Series, Characterizing the Magnetic Activity. Journal of Geophysical Research, 77, 6870-6874. http://dx.doi.org/10.1029/JA077i034p06870

[17] Faynot, J.M. and Vila, P. (1979) F-Region at the Magnetic Equator. Annales Geophysicae, 35, 1-9.

[18] Dunford, E. (1967) The Relationship between the Ionosphere Equatorial Anomaly and the E-Region Current System. Journal of Atmospheric and Terrestrial Physics, 29, 1489-1498. http://dx.doi.org/10.1016/0021-9169(67)90102-X

[19] Vassal, J.A. (1982) Electrojet, contreélectrojet et région F à Sarh (Tchad), Géophysique. ORSTOM, Paris.

[20] Vassal, J. (1982) La variation du champ magnétique et ses relations avec I'électrojet équatorial au Sénégal Oriental. Annales Geophysicae, 3, 347-355.

[21] Acharya, R., Roy, B., Sivaraman, M.R. and Dasgupta, A. (2010) An Empirical Relation of Daytime Equatorial Total Electron Content with Equatorial Electrojet in the Indian Zone. Journal of Atmospheric and Solar-Terrestrial Physics (UK), 72, 774-780. http://dx.doi.org/10.1016/j.jastp.2010.03.023

[22] Acharya, R., Roy, B., Sivaraman, M.R. and Dasgupta, A. (2011) On Conformity of the EEJ Based Ionospheric Model to the Fountain Effect and Resulting Improvements. Journal of Atmospheric and Solar-Terrestrial Physics (UK), 73, 779-784. http://dx.doi.org/10.1016/j.jastp.2011.01.011

[23] Farley, D.T., Bonell, E., Fejer, B.G. and Larsen, M.F. (1986) The Prereversal Enhancement of the Zonal Electric Field in the Equatorial Ionosphere. Journal of Geophysical Research, 91, 13723-13728. http://dx.doi.org/10.1029/JA091iA12p13723

[24] Rishbeth, H. (1971) The F-Layer Dynamo. Planetary and Space Science, 19, 263-267. http://dx.doi.org/10.1016/0032-0633(71)90205-4

[25] Fejer, B.G., Farley, D.T., Woodman, R.F. and Calderon, C. (1979) Dependence of Equatorial F-Region Vertical Drifts on Season and Solar Cycle. Journal of Geophysical Research, 84, 5792-5796.

[26] Fejer, B.G. (1981) The Equatorial Ionospheric Electric Fields: A Review. Journal of Atmospheric and Terrestrial Physics, 43, 377-386. http://dx.doi.org/10.1016/0021-9169(81)90101-X 